$\alpha=45^{\circ}$, where the model occupies 4 per cent of the tunnel cross-section, which should not affect the value of $C_{D}$ greatly. The largest correction for endplates was 2.8 per cent.

The correlation between $C_{D}$, the scale of turbulence relative to the size of cylinder and the intensity of the free stream turbulence are at present under investigation.

Tho drag coefficient and Reynolds number are given by

$$
\begin{gathered}
C_{D}=\text { drag coefficient }=\frac{2 g D}{\rho U^{2} A_{m}} \\
R e=\text { Reynolds number }=\frac{U H(\cos \alpha+\sin \alpha)}{\nu}
\end{gathered}
$$

where $A_{m}=$ projected area in feet" of cylinder, normal to mean air flow, $D=$ measured drag (pounds-force), $H$, length of side of square (feet), $L$, length of cylinder (feet), $U$, mean free stream velocity, $\alpha$, angle of incidence between top face of cylinder and mean wind direction (dogrees), $\rho$, air density, and $v$, kinematic viscosity.

We thank the Science Research Council and the Department of Mechanical Engineering, University of Nottingham, for support.

F. G. McLaren

A. F. C. SherratT

A. S. MORTON

Building Science Laboratories,

Department of Architecture and Civic Planning, University of Nottingham.

Received May 6, 1969.

${ }^{3}$ Delany, N. K., and Sorensen, N. E., Low Speed Drag of Cylinders of Various Shapes, NACA Tech. Note T'N 3038 (1953).

\section{Preparation and Growth of Single Crystals of Metallic Azides by Controlled Diffusion in Silica Gel System}

STUDIES of the solid state properties of metallic azides are at present restricted by the lack of availability of single crystal specimens because of preparative difficulties. According to reports, lead azide, for example, may explode spontaneously during solution growth, particularly when faster growth rates are used ${ }^{1-3}$. Crystal growth in gels at near ambient temperatures seems to be an attractive technique for growing single crystals of such metal azides $^{4-7}$. In gels, the diffusion controlled growth rates are lower than in solution and convection currents, which may be a causative disturbance for explosions are virtually eliminated.

We report the successful growth of single crystals of lead azide in gels at near ambient temperatures in experimental conditions which reduce or eliminate the preparative hazards of solution growth methods. This techniquo has also been used successfully for growing single thallous azide crystals.

Single crystals of lead azide were grown in silica gels prepared by mixing equal volumes of sodium silicate (Fisher certified reagent) solution of specific gravity 1.06 and $5 \cdot 75$ per cent by weight nitric acid solution. Five ml. of lead nitrate $(0.1 \mathrm{M})$ was added for each $20 \mathrm{ml}$. of this mixture. The resulting solution, adjusted to a $\mathrm{pH}$ of 6.5 if necessary, was poured into $25 \mathrm{~mm}$ diameter standard test tubes and permitted to gel-which occurred within 5 to $10 \mathrm{~min}$. 'This gel was allowed to stand for an additional 1 to $2 \mathrm{~h}$, in order to enhance its mechanical strength and resistance to deformation. An additional amount of the gel forming mixture, also made by mixing equal volumes of 1.06 specific gravity sodium silicate solution and 5.75 per cent by weight nitric acid but containing no lead nitrate, was placed on this gel and permitted to gel. The ratio of the original gel volume to this second top gel volume was approximately $1: 1$.
The resulting two layer gel system was covered with $5 \mathrm{ml}$. sodium azide solution $(0 \cdot 2 \mathrm{M})$, parmitting the azide ions to diffuse into the gel and react with the lead ions. Experiments were carried out at constant temperatures ranging from $25^{\circ}$ to $55^{\circ} \mathrm{C}$ with the gel systems being examined periodically for evidence of crystal growth.

At $50^{\circ} \mathrm{C}$ lead azide crystals become visible to the naked eye after 5 to 7 days. After 2 weeks colourless crystals about $1 \cdot 5-2 \mathrm{~mm}$ in size were attained. Using appropriate analytical methods these were identified as single crystals of orthorhombic alpha lead azide. Chemical purity was ascertained by carefully heating selected crystals to approximately $200^{\circ} \mathrm{C}$ for conversion to lead oxide which was then evaluated spectrographically. Although standard grade, reagents that were not specially purified were used in these erystal growth studies; the total metallic impurity content was in the order of 10-20 p.p.m., chiefly iron, silver and some silicon.

Growth experiments at $25^{\circ} \mathrm{C}$ resulted in substantially higher nucleation rates due to the higher supersaturations, and the resulting crystals were opaque. Numerous individual experiments were thus carried out without any case of spontaneous explosion.

Thallous azide single crystals were grown following essentially the same procedure except that the bottom gel layer was prepared by mixing the sodium silicate solution with the nitric acid solution containing $5 \mathrm{ml}$. of $0.4 \mathrm{M}$ thallous nitrate solution. Five ml. of a $\mathrm{I} \mathrm{M}$ sodium azide solution was poured on the top gel layer and permitted to diffuse into the gel as before. Satisfactory results were obtained at $50^{\circ} \mathrm{C}$ where two to four crystals of thallous azide were obtained per $20 \mathrm{ml}$. of gel, after 3 to 4 days. These continued to grow to $3-4 \mathrm{~mm}$ size within a week. The identity of these pale yellow transparent tetragonal bipyramids was confirmed by appropriate analyses.

Experimental studies are continuing in order to obtain larger and more perfect high purity crystals. We thank the Explosive Chemistry Branch Laboratory, Picatinny Arsenal, for the financial support of this work.

\section{DEEPAK RANADIVE ZVI BLANK \\ Walter Brenner Yoshryuki OKamoto}

Research Division,

School of Engineering and Science,

New York University,

Bronx, New York.

Received April 28; revised June 19, 1969.

1 Bowden, F. P., and Yoffe, A. D., Fast Reactions in Solids (Academic Press, Inc., Ni).

${ }_{2}^{2}$ Taylor, G. W. C., and Thomas, A. T., J. Cryst. Growth, 3, 4, 391 (1968).

${ }^{3}$ McCrone, W. C., Associates, The Growth of Azide Crystals, Rep. under contract No. DA-44-009ENG 4567 US Army Engineering Research and Development Laboratories, Fort Beludir, Va.

${ }^{4}$ Blank, Z., Brenner, W., and Okamoto, Y., Mat. Res. Bull., 3, 555 (1968).

'Blank, Z., Brenner, W., and Okamoto, Y., J. Cryst. Crrowth, 3, 4, 372 (1968).

${ }^{6}$ Henisch, J. K., Dennis, J., and Hanoka, J. Y., J. Phys. Chem. Solids, 26, 493 (1965).

'DiPictro, M. A., O’Conner, J. J., and Rabin, B., Air Force Cambridge lies. Lab., Bedford, Massachusetts, Phys. Sci. Res. Pap. No. 227, May (1966).

\section{Thermal Stability of Metal Hydrides, Deuterides and Tritides}

INTEREST in the stability of metal hydride materials has bsen stimulated by their potential use as reactor moderators and as target materials in neutron generating devices which could find widespread application in compact activation analysis equipment. Earlier work has scanned the thermal stability of most rare earth and yttrium dihydrides and dideuterides ${ }^{1-6}$, and the effects of varying the rare earth metal on the heats and entropies of formation have been discussed in terms of lattice energies and 